\title{
Effects of Hot-Water Extract of Paecilomyces hepiali on Hypertension Parameters in Spontaneously Hypertensive Rats
}

\author{
Alfred Chioza, Shoji Ohga \\ Department of Agro-Environmental Sciences, Faculty of Agriculture, Kyushu University, Fukuoka, Japan \\ Email: ohga@forest.kyushu-u.ac.jp
}

Received 23 April 2014; revised 23 May 2014; accepted 31 May 2014

Copyright (C) 2014 by authors and Scientific Research Publishing Inc.

This work is licensed under the Creative Commons Attribution International License (CC BY). http://creativecommons.org/licenses/by/4.0/

(c) (i) Open Access

\begin{abstract}
In this study, effects of hot water extract of Paecilomyces hepiali mycelia on hypertension parameters in spontaneously hypertensive rats (SHR) were investigated. The tested parameters included blood pressure, blood and urine biochemical composition, renin and angiotensin II levels in the blood. Prior to these tests, the extract was examined for toxicity. The fungus was cultivated in a solid medium composed of $40 \mathrm{~g}$ brown rice, $0.32 \mathrm{~g}$ glucose, $0.65 \mathrm{~g}$ sucrose, $2 \mathrm{~g}$ peptone and $65 \mathrm{ml}$ corn steep liquor. No abnormality or harmful effects were observed in the toxicity test. Administration of a continuous-dose, once daily, to SHR for 27 weeks (from 13 weeks of age) decreased the systolic blood pressure (SBP) significantly. Levels of blood urea nitrogen, $\beta$-lipoprotein lipid peroxides and low density lipoprotein were significantly lower in the treated groups when compared to the control group. Urinary protein was significantly reduced in the middle and high dose groups. In comparison with the control group $(0 \mathrm{mg} / \mathrm{kg} / 10 \mathrm{ml} /$ day $)$, significantly higher values were obtained for total cholesterol in groups that were given middle $(170 \mathrm{mg} / \mathrm{kg} / 10 \mathrm{ml} / \mathrm{day})$ and high $(250 \mathrm{mg} / \mathrm{kg} / 10 \mathrm{ml} /$ day) dosages. In all dosages (low, middle and high) the values for triglyceride were significantly higher than value found in the control group. In terms of angiotensin II levels, the value in the control group was markedly higher than values in the other groups. The results suggest that oral administration of hot water extract of $P$. hepiali mycelia has ability to control hypertension in rats.
\end{abstract}

\section{Keywords}

Hot-Water Extract, Paecilomyces hepiali, Ophiocordyceps sinensis, Spontaneously Hypertensive Rats 


\section{Introduction}

A number of fungi have been described as anamorphs of Ophiocordyceps sinensis (former name: Cordyceps sinensis). Since the 1980s 22 species in 13 genera have been attributed to the anamorph of $O$. sinensis [1]. These include Stachybotrys sp., Paecilomyces sinensis, Scytalidium hepiali, Tolypocladium sinensis, Chrysosporium sinensis, Hirsutella sinensis, Synnematium sinensis, Cephalosporium sp., Paecilomyces hepiali, Mortierella hepiali, and Scytalidium hepiali [2]. These species have been used for mass production of mycelia for making various commercial products labelled as $O$. sinensis or $C$. sinensis. Chen et al. [2] describes the labelling of mycelia products from all these isolates as $O$. sinensis or $C$. sinensis to be confusing to the consumer because at the moment it is only $H$. sinensis and not the other isolates which have been confirmed as the correct anamorph of $O$. sinensis [3]-[5].

Paecilomyces hepiali has been popularly used as an anamorph of $O$. sinensis. Most of the reported medicinal benefits of artificially cultivated mycelia of $O$. sinensis are based on clinical trials which had been done on $P$. hepiali Chen (strain Cs-4). The aseptically fermented mycelia of $P$. hepiali Chen (strain Cs-4) underwent extensive human testing and clinical trials during the 1980s and resulted in a popular commercial product in China, which was known as Jin-Shui-Bao capsule [6]. However, current reports are discarding this fungus as a correct anamorph of $O$. sinensis. As indicated earlier, $H$. sinensis is currently receiving general acceptance as the right anamorph of this mushroom [3]-[5].

Spontaneously hypertensive rats (SHR) are the most often used species in hypertension research. SHR is a rat model that reflects a primary human hypertension that is inherited in a Mendelian manner [7]. Antihypertensive actions in SHR have been reported for mushrooms such Pleurotus nebrodensis, Ganoderma lucidum, Lentinula edodes and Mycoleptodonoides aitchisonii [8] [9]. It has been suggested that mushrooms lower blood pressure by improving lipid metabolism and kidney function and hindering angiotensin-converting enzymes [10]. As reported by Miyazawa et al. [8], the strength of antihypertensive actions varies with species. Midoh et al. [11] established that repeated once-daily doses of Porcini (Boletus aestivalis) mushrooms have a stronger blood pressure-lowering effect than that of Agaricus blazei, Lentinula edodes, Lyophyllum decastes and Pleourotus eryngii in SHR.

In this study, effects of hot water extract of $P$. hepiali mycelia on hypertension related parameters in spontaneously hypertensive rats (SHR) were investigated. The studied parameters included blood pressure, blood and urine biochemical changes, and renin and angiotensin II levels in the blood. Prior to the aforementioned studies, the hot water extract of the fungus was evaluated for toxicity using ICR rats.

\section{Materials and Methods}

\subsection{Fungal Material}

The fungal strain used in this study was acquired from the mushroom culture bank at the Laboratory of Forest Resources Management, Kyushu University. It is assigned to accession number KUMB108 in the culture bank.

\subsection{Preparation of Mycelial Powder}

A solid substrate ( $40 \mathrm{~g}$ brown rice, $0.325 \mathrm{~g}$ glucose, $0.65 \mathrm{~g}$ sucrose, $2 \mathrm{~g}$ peptone and $65 \mathrm{ml}$ corn steep liquor) was used to grow mycelia of $P$. hepiali. The fully colonised substrate was freeze dried before being ground to powder using a Waring blender. The extraction was done using this powder.

\subsection{Toxicity Test}

Acute (14 days), subchronic (90 days) and chronic (52 weeks) toxicity tests were carried out in order to evaluate toxicity of $P$. hepiali extract. Five weeks old ICR rats, which were purchased from Charles River Laboratories (Japan) Inc., were used. The animals were tested in accordance with OECD (Organisation for Economic Cooperation and Development) guidelines for the testing of chemical products. The extract was administered orally at dose levels of 0 (control), 500, 1000 and $2000 \mathrm{mg} / \mathrm{kg}$. Treatments were initiated after allowing the animals a week of acclimatization. Twelve animals (six male and six females) were used per dose. Animals on the same dose were housed in the same cage. The housing environment was maintained at $22^{\circ} \mathrm{C}$ temperature and 12 hours of light time per day. The animals were provided unrestricted access to feed (MF Oriental Yeast Co.) and tap water. Before commencing treatments, animals were fasted for about 6 hours. At the start of administration of 
doses, the body weight ranges for male and female animals were 30.3 - $34.8 \mathrm{~g}$ and 23.4 - $26.5 \mathrm{~g}$ respectively. During the test period, all animals were observed on daily basis for mortality, appearance and signs of intoxication. At the end of test period blood samples were collected from the animals before sacrificing them in order to examine internal organs. Blood samples were subjected to blood chemistry analyses.

\subsection{Systolic Blood Pressure and Biochemical Analyses of Blood and Urine}

\subsubsection{Experimental Animals}

Seven week old male spontaneously hypertensive rats (SHR) purchased from Charles River Laboratories Japan, Inc. were used in this study. The animals were kept at $22^{\circ} \mathrm{C} \pm 1{ }^{\circ} \mathrm{C}$ temperature, $60 \% \pm 10 \%$ humidity, 12 hours light time (from 7:00 am) and 12 hours dark time (from 7:00 pm). The animals were allowed a one week period of acclimatization before applying any experimental treatment. During this period, they were fed on MF Powder (Oriental Yeast Co., Ltd, Tokyo, Japan) and given access to distilled water. MF Powder supplemented with 8\% Sodium Chloride was given to the animals from 9 to 13 weeks of age to raise their blood pressure.

\subsubsection{Administration of Doses}

After 13 weeks of age the animals were divided into four groups based on treatments: Low dose $(5 \mathrm{~g} / 60 \mathrm{~kg} /$ $600 \mathrm{ml} /$ day $)$, medium dose $(10 \mathrm{~g} / 60 \mathrm{~kg} / 600 \mathrm{ml} /$ day $)$, high dose $(15 \mathrm{~g} / 60 \mathrm{~kg} / 600 \mathrm{ml} /$ day $)$ and control $(0 \mathrm{~g} / 60 \mathrm{~kg} /$ $600 \mathrm{ml} /$ day). Each group was composed of five animals $(n=5)$. These doses were applied to the groups for 27 weeks (13 - 40 weeks). The hot water extract, at dose levels mentioned above, were given to the animals, once daily, by oral administration. All the groups had free access to MF Powder and distilled water.

The hot water extract for the low dose was made by adding $5 \mathrm{~g}$ of $P$. hepiali dry powder into $600 \mathrm{ml}$ of distilled water. The resulting solution was then held in a water bath at $80^{\circ} \mathrm{C}$ for 1 hour. After cooling, the supernatant was filtered. The filtrate was placed in a flask and brought to $600 \mathrm{ml}$ by adding distilled water. The extracts for medium and high doses were made by adding $10 \mathrm{~g}$ and $15 \mathrm{~g}$ respectively. The human weight-based doses of $5 \mathrm{~g} / 60 \mathrm{~kg} / 600 \mathrm{ml} /$ day (low dose), $10 \mathrm{~g} / 60 \mathrm{~kg} / 600 \mathrm{ml} /$ day (medium dose) and $15 \mathrm{~g} / 60 \mathrm{~kg} / 600 \mathrm{ml} /$ day (high dose) were converted to rat doses of $80 \mathrm{mg} / \mathrm{kg} / 10 \mathrm{ml} /$ day (low dosage), $170 \mathrm{mg} / \mathrm{kg} / 10 \mathrm{ml} /$ day (middle dosage) and $250 \mathrm{mg} / \mathrm{kg} / 10 \mathrm{ml} /$ day (high dosage) respectively.

\subsubsection{Measurement of Blood Pressure}

Measurements of systolic blood pressure (SBP) of rats were made using the non-invasive tail-cuff method (BP98A, Softron) at the end of 27 weeks after commencement of treatments. The SBP for each animal was recorded as an average of three measurements. All measurements were done in a room with constant temperature and humidity between 11:00 am and 4:00 pm.

\subsubsection{Blood and Urine Tests}

Animals were deeply anaesthetised (Nembutal, $45 \mathrm{mg} / \mathrm{kg}$ ) after fasting them from the previous day. Blood sample was drawn from the left ventricle of each animal using a 20G blood drawing needle. Blood samples were subjected to biochemical (Automatic Chemical Analyser: Auto Lab, Radio Immuno Assay) and endocrinology tests. The Endocrinology test was conducted by using Radio Immuno Assay (RIA) to measure renin and angiotensin II levels in the blood. Urine samples, which were collected two days before the end of the test, were analysed for urinary protein content.

\subsection{Data Analysis}

All data, apart from that on blood analysis of ICR rats after toxicity test, are presented as mean \pm standard error (SE). Data for blood and urine biochemical analyses were subjected to Analysis of Variance (ANOVA) followed by Tukey's test $(\mathrm{p}<0.05)$ using Minitab 17 statistical software (Minitab Inc.). All graphs are presented with standard error bars.

\section{Results and Discussion}

\subsection{Toxicity Test}

This test was conducted to find out if hot water extract of $P$. hepiali has toxic effects in rats. No abnormality or 
sing(s) of toxicity was observed in all internal organs which were inspected. These included the liver and kidneys. As shown in Table 1, blood analyses for all doses at the end of toxicity test did not show any significant deviations from the control group. No abnormalities in behaviour or external appearance were observed in the animals throughout the test period. These results and observations confirm that the hot-water extract of $P$. hepiali is a nontoxic substance.

\subsection{Systolic Blood Pressure (SBP)}

Three dose levels (Low dosage: $80 \mathrm{mg} / \mathrm{kg} / 10 \mathrm{ml} /$ day, Middle dosage: $170 \mathrm{mg} / \mathrm{kg} / 10 \mathrm{ml} /$ day and High dosage: 250 $\mathrm{mg} / \mathrm{kg} / 10 \mathrm{ml} /$ day) plus control ( $0 \mathrm{mg} / \mathrm{kg} / 10 \mathrm{ml} /$ day) were orally administered to Spontaneously Hypertensive Rats (SHR) for 27 weeks from 13 weeks of age. Figure 1 shows systolic blood pressure values of rats at 40 weeks of age in all the four groups. The value in the control group was significantly higher than the other three groups in which the extract had been administered. This shows that the hot water extract of $P$. hepiali lowered SBP levels in SHR. The blood pressure lowering ability of the fungus increased with increasing dosage. The results of studies with Agaricus blazei dry powder [12], Lentinula edodes, Lyophyllum decastes and Pleurotus nebrodensis [10] showed that the antihypertensive effects of macrofungi in SHR are dose dependant. The present study has also confirmed the same with $P$. hepiali. It has been suggested that mushrooms lower blood pressure by improving lipid metabolism and kidney function and hindering angiotensin-converting enzymes [10].

\subsection{Blood and Urine Biochemical Analyses}

Table 2 shows results of comparative biochemical analyses of blood and urine samples which were drawn from all the four test groups of rats at the age of 40 weeks. As presented in the Table 2, levels of blood urea nitrogen, $\beta$-lipoprotein lipid peroxides and low density lipoprotein were significantly lower in the treated groups as compared to the control group. Urinary protein was significantly reduced only in the middle and high dose groups. In comparison with the control group $(0 \mathrm{mg} / \mathrm{kg} / 10 \mathrm{ml} / \mathrm{day})$, significantly higher values were obtained for total cholesterol in groups that were given middle $(170 \mathrm{mg} / \mathrm{kg} / 10 \mathrm{ml} /$ day $)$ and high ( $250 \mathrm{mg} / \mathrm{kg} / 10 \mathrm{ml} /$ day $)$ dosages. In

\section{Table 1. Blood analysis of ICR rats after toxicity test.}

\begin{tabular}{|c|c|c|c|c|}
\hline \multirow{2}{*}{ Blood Component } & \multicolumn{4}{|c|}{ Dose levels } \\
\hline & Control & $500 \mathrm{mg} / \mathrm{kg}$ & $1000 \mathrm{mg} / \mathrm{kg}$ & $2000 \mathrm{mg} / \mathrm{kg}$ \\
\hline Serum protein & 4.33 & 4.23 & 4.33 & 4.45 \\
\hline $\mathrm{A} / \mathrm{G}$ & 2.133 & 2.153 & 2.121 & 2.154 \\
\hline AST (GOT) & 168.90 & 168.30 & 168.12 & 189.64 \\
\hline AST (GTP) & 211.80 & 212.10 & 211.30 & 211.20 \\
\hline LDH & 2114.10 & 2234.10 & 2123.10 & 2131.10 \\
\hline Colin esterase & 1989.30 & 1842.10 & 1991.20 & 1998.30 \\
\hline $\mathrm{T}-\mathrm{CHO}$ & 124.30 & 132.10 & 128.31 & 133.42 \\
\hline TG & 127.80 & 130.30 & 133.20 & 124.80 \\
\hline HDL & 79.80 & 78.90 & 79.20 & 80.30 \\
\hline LDL & 6.11 & 6.02 & 6.11 & 6.03 \\
\hline BUN & 78.90 & 69.20 & 75.40 & 73.41 \\
\hline Creatin & 1.07 & 1.08 & 1.09 & 1.08 \\
\hline Urea & 3.66 & 3.24 & 3.38 & 3.66 \\
\hline White blood cells & 4.15 & 4.08 & 4.09 & 4.23 \\
\hline Blood platelets & 32.58 & 32.34 & 32.57 & 32.72 \\
\hline
\end{tabular}


Table 2. Effects of $P$. hepiali hot water extract on biochemical changes in blood and urine of spontaneously hypertensive rats.

\begin{tabular}{ccccc}
\hline Component & \multicolumn{3}{c}{ Dosage } \\
\cline { 2 - 4 } & Control & Low & Middle & High \\
\hline Total cholesterol (mg/dl) & $56 \pm 1.0$ & $57 \pm 0.3$ & $68 \pm 0.8^{*}$ & $69 \pm 1.1^{*}$ \\
Triglyceride (mg/dl) & $17 \pm 0.5$ & $27 \pm 0.9^{*}$ & $30 \pm 0.9^{*}$ & $31 \pm 0.9^{*}$ \\
$\beta$-lipoprotein (mg/dl) & $36 \pm 1.4$ & $35 \pm 1.5$ & $26 \pm 1.4^{*}$ & $28 \pm 1.0^{*}$ \\
Low Density Lipoprotein (mg/dl) & $74 \pm 2.7$ & $55 \pm 1.9^{*}$ & $49 \pm 1.2^{*}$ & $43 \pm 1.4^{*}$ \\
$\beta$-lipoprotein lipid peroxides (nmol/ml) & $4.3 \pm 0.1$ & $3.2 \pm 0.1^{*}$ & $2.7 \pm 0.1^{*}$ & $2.4 \pm 0.1^{*}$ \\
Blood urea nitrogen (mg/dl) & $26 \pm 0.5$ & $17 \pm 0.1^{*}$ & $15 \pm 0.1^{*}$ & $13 \pm 0.1^{*}$ \\
Urinary protein (mg/dl) & $6.3 \pm 0.1$ & $6.1 \pm 0.2$ & $4.9 \pm 0.1^{*}$ & $4.3 \pm 0.2^{*}$ \\
\hline
\end{tabular}

Control: $0 \mathrm{mg} / \mathrm{kg} / 10 \mathrm{ml} /$ day, Low dosage: $80 \mathrm{mg} / \mathrm{kg} / 10 \mathrm{ml} /$ day, Middle dosage: $170 \mathrm{mg} / \mathrm{kg} / 10 \mathrm{ml} /$ day, High dosage: $250 \mathrm{mg} / \mathrm{kg} / 10 \mathrm{ml} / \mathrm{day}$. Each value expresses the mean $\pm \mathrm{SE}(\mathrm{n}=5)$. Any value with an asterisk $\left(^{*}\right)$ is significantly different with the control group within the tested component, Tukey's test $(\mathrm{p}<0.05)$.

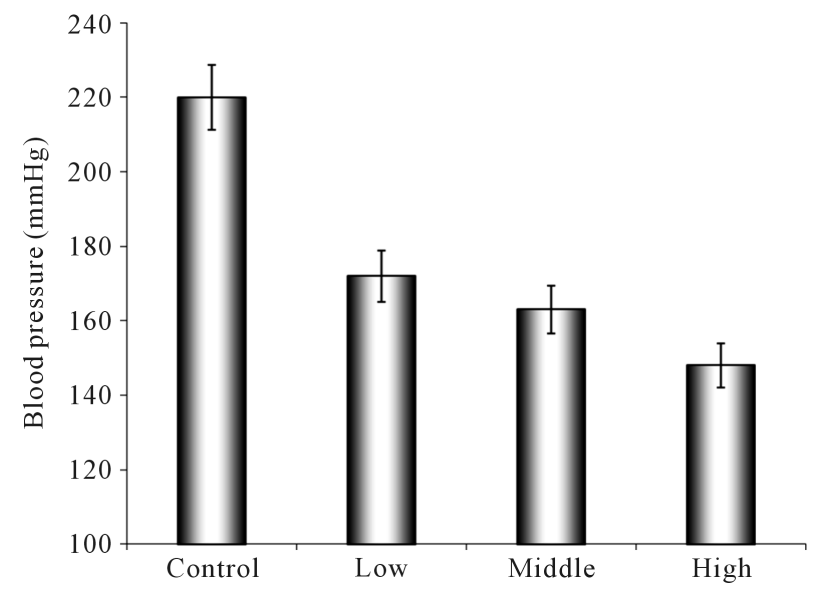

Figure 1. Systolic blood pressure in spontaneously hypertensive rats. Cont: Control $(0 \mathrm{mg} / \mathrm{kg} / 10 \mathrm{ml} /$ day $)$, Low: Low dosage $(80 \mathrm{mg} / \mathrm{kg} / 10 \mathrm{ml} /$ day), Middle: Middle dosage (170 $\mathrm{mg} / \mathrm{kg} / 10 \mathrm{ml} /$ day), High: High dosage (250 mg/kg/10ml/day). Error bars represent standard error $(n=5)$.

all dosages (low, middle and high) the values for triglyceride were significantly higher than value found in the control group.

Urea is produced in the liver of vertebrates and some other animals as a waste product of protein metabolism. As the blood passes through the kidneys, urea is taken out of the body through urine. As indicted by Miyazawa et al. [10], blood urea nitrogen (BUN) is used as an indicator of kidney function and an increase in urea nitrogen may affect protein metabolism. In this study, BUN levels in all the groups which were given $P$. hepiali hot water extract were significantly lower than the value in the control group. Midoh et al. [11] found that administration of hot water extract of Boletus aestivalis brought about reductions of BUN and creatinine (Cre) in SHR, which are indictors of renal clearance, suggesting that the mushroom may act to improve the renal function. The lower BUN values in the groups which were given $P$. hepiali extract in this study may also be suggesting that this fungus has ability to improve the renal function in SHR.

A small quantity of low molecular weight proteins are allowed to filtrate in a normal kidney and most of them are reabsorbed in tubules. The presence of high amounts of proteins in urine could be a sign of an important renal disease [13]. In this study, significantly lower values of urinary protein were obtained in the middle and high dosage groups as compared to the control group. This finding would be suggesting that the hot water extract of 
P. hepiali has improvement effect on the renal system in SHR. However, it should be noted that this study did not look at the actual mechanism(s) involved in this effect.

A renal system that is not functioning well may result in reduced sodium excretion and thereby bringing about an elevation of blood pressure, while an elevated blood pressure may lead to nephrosclerosis and subsequent impairment of the renal function [14] [15]. Results on blood and urine biochemical analysis, especially with regard to urinary protein and blood urea nitrogen (BUN), in the groups that were given the hot water extract of $P$. hepiali may be suggesting that this fungus improved the renal system which may have resulted in the reduced blood pressure in SHR. It may also be the other way round; the lower blood pressure values recorded in rats which were given the fungus' extract may have improved the renal system. Further studies need to be done to ascertain that.

In comparison with the control group, the values for total cholesterol and triglyceride (blood lipids) were significantly higher in all groups which had been given the extract (Table 2). However, low density lipoprotein (LDL) levels were significantly lower in the low, middle and high dosage groups as compared to the control group. LDL is known as "bad" cholesterol [16] because high levels of this cholesterol can lead to atherosclerosis and cardiovascular disease [17]. As described by Reddin [18], hypertension can cause atherosclerosis and atherosclerosis causes high blood pressure. In atherosclerosis condition the heart requires greater pumping to allow blood pass through the arteries which have lost elasticity and that elevates blood pressure. On the other hand, elevated blood pressure can cause damage to the surface cells lining the inside of arteries and this condition is thought to initiate atherosclerosis. In the present study both SBP and LDL were significantly lower in groups which were given the extract as compared to control. There is a possibility that one of these had a lowering effect on the other.

\subsection{Renin and Angiotensin II Levels}

Renin level in the control group was significantly lower than all values in the other groups which were given the hot water extract of $P$. hepiali (Figure 2(a)). The value was highest in the middle dosage group followed by the low dosage group. In terms of angiotensin II levels, the value in the control group was markedly higher than values in the other groups (Figure 2(b)).

Renin, which is secreted by the kidneys when low blood volume is detected, stimulates production of angiotensin I, which is converted into angiotensin II. Among other effects, angiotensin II increases blood pressure. In the present study, the level of angiotensin II in the control group was significantly higher than in the groups that were given the extract. As shown in Figure 1, the control group also had a significantly higher SBP value than the treated groups. This may be demonstrating the involvement of angiotensin II in raising SBP. As indicated by Midoh et al. [11], the ingredients in natural mushrooms which are reported as being responsible for lowering

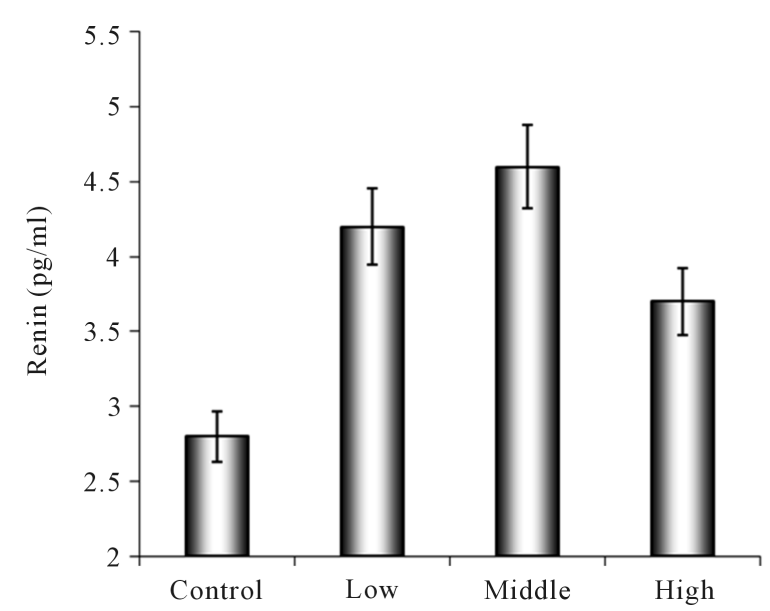

(a)

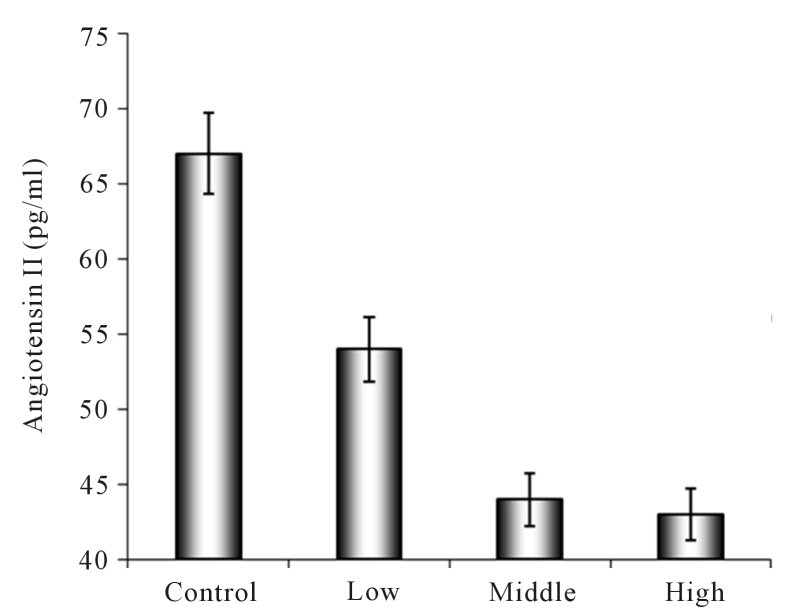

(b)

Figure 2. Effect of hot water extract of $P$. hepiali on (a) renin and (b) angiotensin II levels in SHR. Control: $0 \mathrm{mg} / \mathrm{kg} / 10 \mathrm{ml} /$ day, Low dosage: $80 \mathrm{mg} / \mathrm{kg} / 10 \mathrm{ml} /$ day, Middle dosage: $170 \mathrm{mg} / \mathrm{kg} / 10 \mathrm{ml} /$ day, High dosage: $250 \mathrm{mg} / \mathrm{kg} / 10 \mathrm{ml} /$ day. Error bars represent standard error $(n=5)$. 
blood pressure include peptides. This effect is achieved through inhibition of angiotensin conversion.

\section{Conclusion}

This study has confirmed that the hot water extract of $P$. hepiali mycelia is nontoxic substance. It has also demonstrated possibilities of improvement effect on the renal function in SHR. The high blood pressure-lowering ability has also been shown. However, the study did not look at the actual active compounds in the fungus that would be responsible for these effects. The mechanism of the involved active compound(s) also needs to be investigated in future researches.

\section{References}

[1] Jiang, Y. and Yao, Y.J. (2002) Names Related to Cordyceps sinensis Anamorph. Mycotaxon, 84, 245-254.

[2] Chen, C.-S., Hseu, R.-S. and Huang, C.-T. (2011) Quality Control of Cordyceps sinensis Teleomorph, Anamorph, and Its Products. In: Shoyama, Y., Ed., Quality Control of Herbal Medicines and Related Areas, InTech. http://www.intechopen.com/books/quality-control-of-herbal-medicines-and-related-areas/quality-control-of-cordycepssinensis-teleomorph-anamorph-and-its-products

[3] Liu, Z.-Y., Liang, Z-Q., Liu, A.-Y., Yao, Y.-J., Hyde, K.D. and Yu, Z-N. (2002) Molecular Evidence for Teleomorph-Anamorph Connections in Cordyceps Based on ITS-5.8S rDNA Sequences. Mycological Research, 106, 1100-1108. http://dx.doi.org/10.1017/S0953756202006378

[4] Liu, Z.-Y., Yao, Y.-J., Liang, Z.Q., Pegler, D.N. and Chase, M.W. (2001) Molecular Evidence for the AnamorphTeleomorph Connection in Cordyceps sinensis. Mycological Research, 105, 827-832. http://dx.doi.org/10.1017/S095375620100377X

[5] Liang, Z.Q. (1991) Anamorphs of Cordyceps and Determination of the Relationship between Anamorph and Teleomorph. Journal of Southwest Agriculture, 4, 1-8.

[6] Holliday, J.C., Cleaver, P., Loomis-Powers, M. and Patel, D. (2004) Analysis of Quality and Techniques for Hybridization of Medicinal Fungus Cordyceps sinensis (Berk.) Sacc. (Ascomycetes). International Journal of Medicinal Mushrooms, 6, 151-164. http://dx.doi.org/10.1615/IntJMedMushr.v6.i2.60

[7] Pinto, Y.M., Paul, M. and Ganten, D. (1998) Lessons from Rat Models of Hypertension: From Goldblatt to Genetic Engineering. Cardiovascular Research, 39, 77-88. http://dx.doi.org/10.1016/S0008-6363(98)00077-7

[8] Miyazawa, N., Eguchi, F., Ohga, S. and Sudo, K. (2005) The Inhibitory Effects of the Fruit Body Hot Water Extracts of Several Mushroom Species on the Hypertension Seen in the Spontaneously Hypertensive Rats. Mushroom Science and Biotechnology, 13, 181-187.

[9] Kabir, Y., Yamaguchi, M. and Kimura, S. (1987) Dietary Effect of Ganoderma lucidum Mushroom on Blood Pressure and Lipid Levels in Spontaneously Hypertensive Rats (SHR). Journal of Nutritional Science and Vitaminology, 33, 341-346. http://dx.doi.org/10.3177/jnsv.33.341

[10] Miyazawa, N., Okazaki, M. and Ohga, S. (2008) Antihypertensive Effect of Pleurotus nebrodensis in Spontaneously Hypertensive Rats. Journal of Oleo Science, 57, 675-681.

[11] Midoh, N., Miyazawa, N. and Eguchi, F. (2013) Effects of a Hot-Water Extract of Porcini (Boletus aestivalis) Mushrooms on the Blood Pressure and Heart Rate of Spontaneously Hypertensive Rats. Bioscience, Biotechnology, and Biochemistry, 77, 1769-1772. http://dx.doi.org/10.1271/bbb.130085

[12] Eguchi, F., Watanabe, Y., Zhang, J., Miyamoto, K., Yoshimoto, H., Fukuhara, T. and Higaki, M. (1999) Inhibitory Effects of Hot Water Extract from Agaricus blazei Fruiting Bodies (CJ-01) on Hypertension Development in Spontaneously Hypersensitive Rats. Journal of Traditional Medicines, 16, 201-207.

[13] Hazelhoff, M.H., Bulacio, R.P. and Torres, A.M. (2013) Organic Anion Transporter 5 Renal Expression and Urinary Excretion in Rats with Vascular Calcification. BioMed Research International, 2013, Article ID: 283429, 10 p. http://dx.doi.org/10.1155/2013/283429

[14] Matavelli, L.C., Zhou, X. and Frohlich, E.D. (2006) Hypertensive Renal Vascular Disease and Cardiovascular Endpoints. Current Opinion in Cardiology, 21, 305-309.

[15] Takahashi, H., Yoshika, M., Komiyama, Y. and Nishimura, M. (2011) The Central Mechanism Underlying Hypertension: A Review of the Roles of Sodium Ions, Epithelial Sodium Channels, the Renin-Angiotensin-Aldosterone System, Oxidative Stress and Endogenous Digitalis in the Brain. Hypertension Research, 34, 1147-1160. http://dx.doi.org/10.1038/hr.2011.105

[16] American Heart Association (2013) Good vs. Bad Cholesterol. http://www.heart.org/HEARTORG/Conditions/Cholesterol/AboutCholesterol/Good-vs-Bad-Cholesterol_UCM_30556 1_Article.jsp 
[17] Koh, J.-H., Kim, J.-M., Chang, U.-J. and Suh, H.-J. (2003) Hypocholesterolemic Effect of Hot-Water Extract from Mycelia of Cordyceps sinensis. Biological and Pharmaceutical Bulletin, 26, 84-87.

http://dx.doi.org/10.1248/bpb.26.84

[18] Reddin, R. (2012) High Blood Pressure: The Relationship between Atherosclerosis and Hypertension. http://ezinearticles.com/?High-Blood-Pressure:-The-Relationship-Between-Atherosclerosis-and-Hypertension\&id=725 $\underline{9492 .}$ 